\title{
Improved productivity by reduced variation in gas metal arc welding (GMAW)
}

\author{
Anna Ericson Öberg ${ }^{1,2}$ (D) Erik Åstrand ${ }^{3,4}$
}

Received: 20 January 2016 / Accepted: 22 February 2017 / Published online: 7 March 2017

(C) The Author(s) 2017. This article is published with open access at Springerlink.com

\begin{abstract}
The purpose of the research conducted is to describe the consequences of variation in the welding industry and the effect it has on manufacturing productivity. The potential has shown to be hidden in unnecessarily stringent requirements and over-processing. This has been studied in steps: customer requirements, design and analysis, preparation, welding, and assessment. The effect of variation in each step has been analyzed including estimations of its productivity improvement potential. Theoretically, in a perfect situation, with customized requirements and eliminated variation, more than half of all welding could be removed. Such a reduction is certainly neither practical nor possible. However, a sensible, controlled reduction could still have a very high impact. The financial implications are therefore substantial. The improved productivity of the manufacturing resources could be used for business development and increased production. To be able to realize the potential, interdisciplinary efforts are necessary. Management across different functions need to agree on the intended product life and make decisions thereafter.
\end{abstract}

Keywords Variation · Weld · Productivity · Fatigue · Interdisciplinary $\cdot$ Requirements

Anna Ericson Öberg

anna.ericson.oberg@volvo.com

1 Chalmers University of Technology, Gothenburg, Sweden

2 Volvo Construction Equipment, Box 303, SE-671 27 Arvika, Sweden

3 University West, Trollhättan, Sweden

4 Volvo Construction Equipment, Braås, Sweden

\section{Introduction}

The objective of this research is to highlight the consequences of variation in the welding industry and the effect it has on manufacturing cost. The research conducted relates to gas metal arc welded structures with a majority of fillet welds with a throat thickness of at least $5 \mathrm{~mm}$. Variation is present in each process step, and in total the accumulated variation has a vast influence on the total manufacturing cost. The cost potential can be found in unnecessarily stringent requirements and over-processing.

The variation of weld quality definitions are symptomatic for the welding process. Traditionally, weld quality is a relative measure on a better-or-worse scale based on the visual weld appearance, to a large extent lacking clear definitions [1]. This in itself induces uncertainty in design, welding, and quality control, creating unnecessary costs [2]. Important properties connected to the fatigue life of the weld do not translate well into specifications on the drawing, giving a weak link between design and production [3-5]. Quality control and audits focus on the characteristics that can be measured instead of what is important from a fatigue life perspective. This creates a situation where the properties and defects inspected might not be the most important with respect to fatigue life [6].

Depending on how the company is organized, there is a risk that people work in silos, focusing on and optimizing their own area, not the entire process. The research by Koufteros et al. [7] demonstrates that the effects of product development strategies on performance are facilitated by manufacturing processes. It acknowledges the fallacy of considering the impact of product development as simply direct and straightforward without the installation of manufacturing activities proportionate to the demands of product development strategies [7]. The consequences are that entities in the organization set 
off towards different goals, resulting in increased cost. ElMaraghy and AlGeddawy [8] state that changes of both products and the corresponding manufacturing capabilities are strongly associated and that their design and structure should be integrated.

There are common models for calculating welding cost [9, 10]. The occurrence of variation and its effect on the process is, however, not commonly addressed in those models. The focus is rather on mean values or on reaching a minimum value according to the specification. The consequences are that resources are spent on measuring irrelevant properties, thereby losing the opportunity to get the right information necessary for making real improvements. That leads to problems describing the consequences to the various actors in the system because of a lacking common language. Hammersberg and Olsson [11] share the idea of the importance of a common language to address the right issues, exemplified in nondestructive testing of welds.

This paper will highlight the significant potential of cost reduction by using typical cases from the welding industry. The academic contribution is added knowledge concerning the cost of variation applicable to the interface between engineering, production, and management. The insights can be used to improve industrial practice and support sound decision-making in the area of welding.

\section{Background}

The research described in this paper has been conducted in the intersections between several areas related to welding, e.g., design and production.

\subsection{Welding of fatigue-loaded structures}

It is not necessarily the amount of welding that determines the life properties of fatigue-loaded structures. Instead, the welds should admit as smooth a stress flow as possible in the structures. High stresses occur at the welded joints with local stress concentrations at the weld toe or at the weld root. This means that there is a significant potential of improved fatigue properties by local improvements. Cost reduction by relieved requirements outside the critical areas is also possible. The key to this enhancement is to adapt the welding procedures to the load conditions [12]. Nykänen et al. [13] express that the ultimate goal is to produce welds of suitable strength at a reasonable cost. Åstrand [12] shares this idea and has proposed several ways to achieve this. First of all, it is necessary to connect the definition of weld quality with the load cases. A weld with excellent properties for one purpose can have inappropriate properties for another. A weld with proper strength for all load cases will become expensive and not as good as a weld that is produced to offer excellent properties for one specific load condition [12].

\subsection{Definition of weld quality}

Welds are often the weakest area of many complex loadcarrying structures, and the weld quality directly affects the integrity of the structure [13]. It is not obvious how to characterize the parameters that affect the fatigue life integrity of the structure. Björk et al. [1] point out that weld quality, like quality in general, is often assessed by comparisons on a better-or-worse scale. This may work when to choose between alternatives, but to determine weld quality on a single product or a single weld is much more challenging. The reason is that true and unambiguous definitions of weld quality must be established and agreed on, which is not the case. The traditional welding procedures and acceptance limits for a weld have evolved mainly based on the weld quality expected from a skilled welder [14]. This is considered as good workmanship, and the focus is on easily observed, physical characteristics of the weld, rather than the real effects on structural integrity [6]. In an evaluation of six international and national standards of weld quality criteria, it could be concluded that the requirements, in general, are based on workmanship rather than fatigue properties. One standard applies to fitness for purpose, but it is used for nuclear power plants and is not widespread [15].

The biggest problem relates to the fact that a good-looking weld often is a good weld, and a weld with a poor appearance may or may not be a poor weld [16]. In some load cases, when the weld root is critical, a weld with a rough visual appearance according to the traditional judgment is most likely better than a weld with a perfect appearance [12].

\subsection{Variation}

According to Wheeler, variation can be considered as a random and miscellaneous component that undermines simple and limited comparisons [17]. Variation is a change in the output or result of a process. All manufacturing and measurement processes contain variation between people, equipment, processes, and products.

There are two types of variation depending on whether the causes are common or assignable. Assignable causes can often be identified while common causes are numerous and difficult to identify individually. A stable process only contains common variation and is therefore predictable, meaning that the average process value is constant and the variability is controlled. An unstable process is unpredictable and contains one or a few assignable causes of variation. Either the process average or the process variation changes, or both. Depending on wether the process is stable or unstable, different improvement actions are suitable. In an unstable process, 
the assignable causes can be identified and need to be eliminated. In a stable process, however, it is often not possible to make improvements by removing sources of variation. Instead, a change in the process structure is needed. According to Bergman and Klefsjö [18], we too often act on random phenomena and thereby cause even greater variation. Since the actions needed differ between the two types, it is necessary to be able to distinguish whether the process is stable or unstable. Plotting the data in a control chart will assist in deciding whether the process is stable or not.

In welding, there are several examples where one adapts to the worst case without considering the variation, e.g., defining a minimum throat thickness. This leads to an incentive to over-process since the production tries to get the resulting output above the limit without taking the variation into account. Figure 1 shows an example of two processes, one of which has reduced variation due to improvement work. By reducing the variation, the difference between mean and tolerance limits has decreased, resulting in a corresponding reduction of over-processing.

\subsection{Welding cost}

There are several welding cost models available from, e.g., Stenbacka, Weman, and Masmoudi et al. [9, 10, 19]. The welding cost is based on the time it takes to produce the parts and the hourly cost. A major difference compared to, e.g., assembly, is that there are relatively simple formulas available to calculate the cost of welding. The common way to estimate

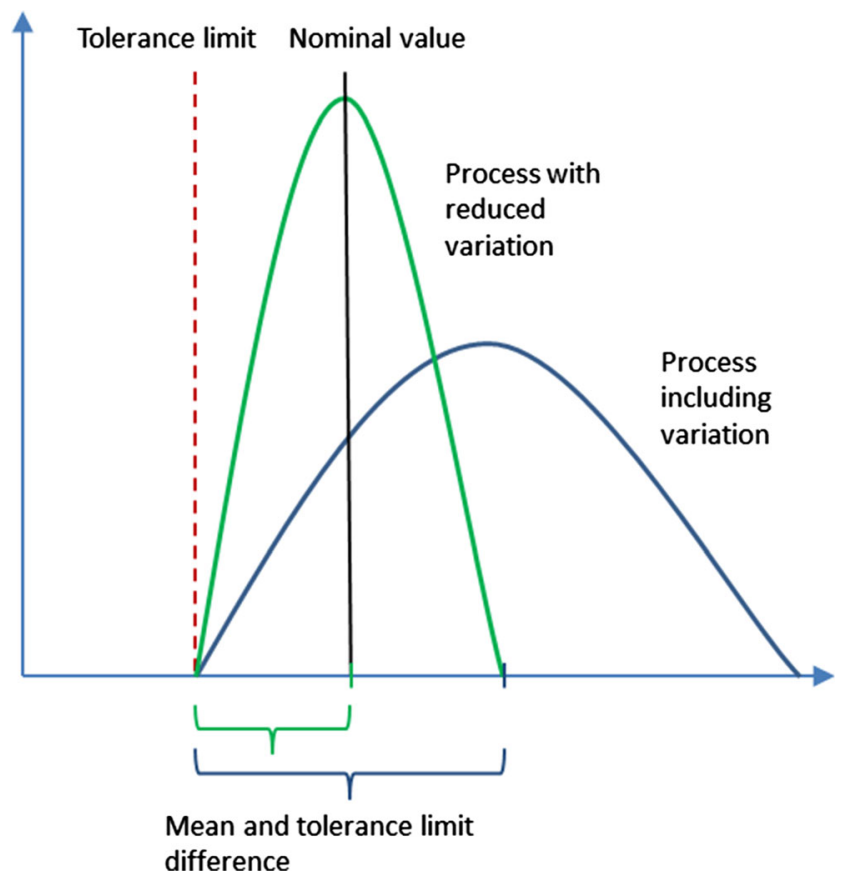

Fig. 1 If the process variation is reduced, the mean value gets closer to the tolerance limit, reducing over-processing the welding cost relates to the following factors, which are considered to be the most important:

- Weld metal $[\mathrm{kg}]$ - the nominal weld metal weight specified on the drawing

- Machine cost $[\cos t / h] — \operatorname{cost}$ per hour for the welding robot

- Deposition rate $[\mathrm{kg} / \mathrm{h}]$ — weld metal deposition per hour

- Arc factor [\%] - the factor of the total time when the arc is struck

The factors are included in the following formula (1), from Weman, which is used in this paper for welding cost estimations [10].

Welding cost $=\frac{\text { Weld metal } * \text { Machine cost }}{\text { Deposition rate*Arc factor }}$

The cost of welding consumables should be added to the cost. Most other costs like, e.g., shielding gas, electricity, and operator costs, are included in the machine cost.

\subsection{The case company}

The studies referred to in this paper have mainly been carried out at a multinational corporation in the construction equipment segment. The studies were conducted with regards to the welding of the load-carrying structures.

\subsection{Research methodology}

The different studies have been of a both quantitative and qualitative character, depending on the intended purpose. The research method used in each study is described in Table 1.

\section{Analysis of variation in the entire value stream}

The sources of variation in the fabrication of welded structures are extensive. Small variations are accumulated during the process, creating large safety margins and over-processing, as illustrated in Fig. 2.

The design under consideration is based on a load-strength model, with the principle of having few failures. The uncertainties in these curves are considerable. In design and analysis, the result could be affected by how the mesh is done. The allowed stress levels from the analysis are typically based on historical data of weld samples with "normal" quality, which in reality is unknown since the definitions are missing [25]. The structure is already affected by the variation, even before it has become a physical product. Each step in the process adds variation. 


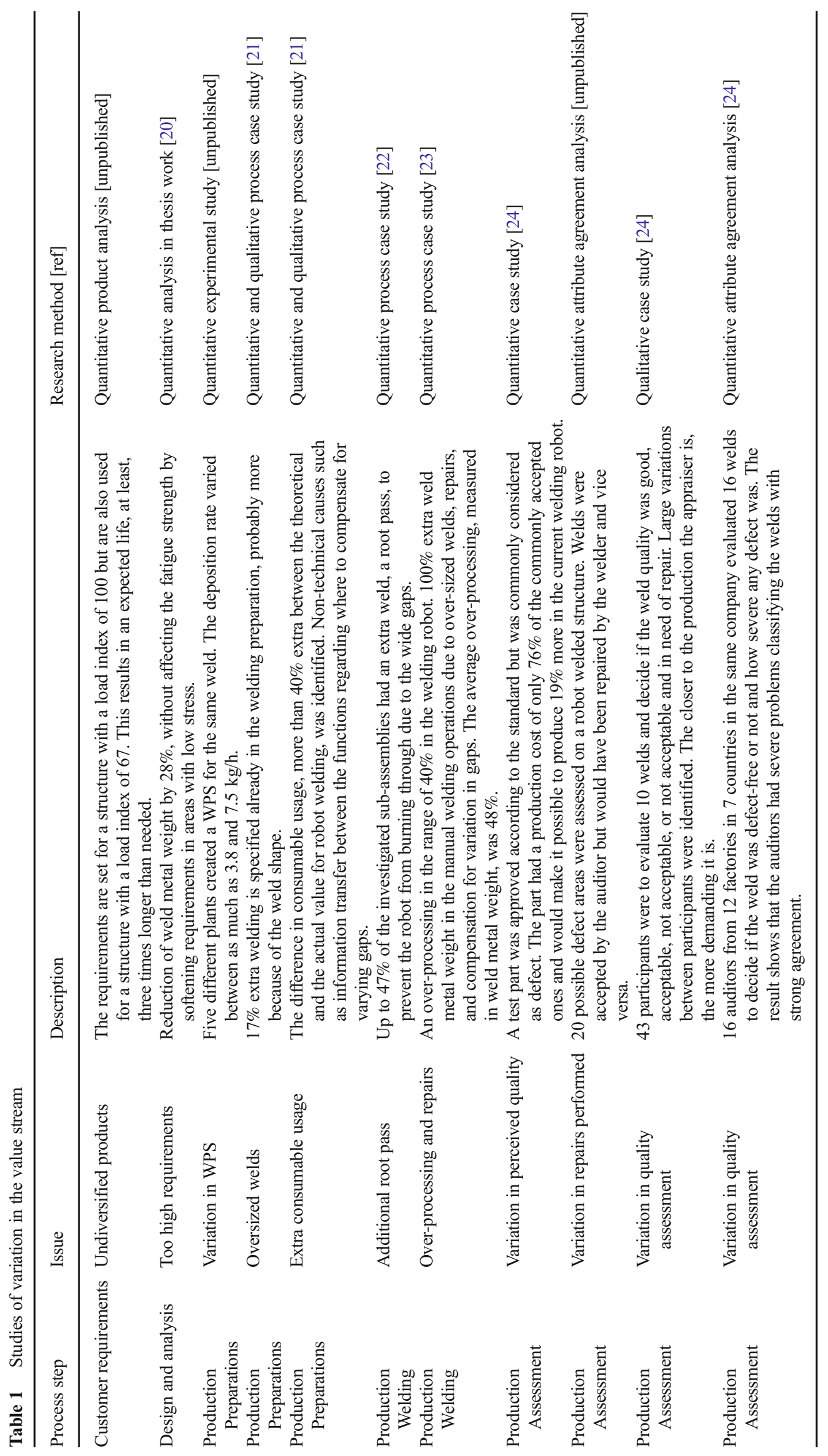


Fig. 2 Illustration of the accumulation of variation and safety margins in the value stream of welded structures

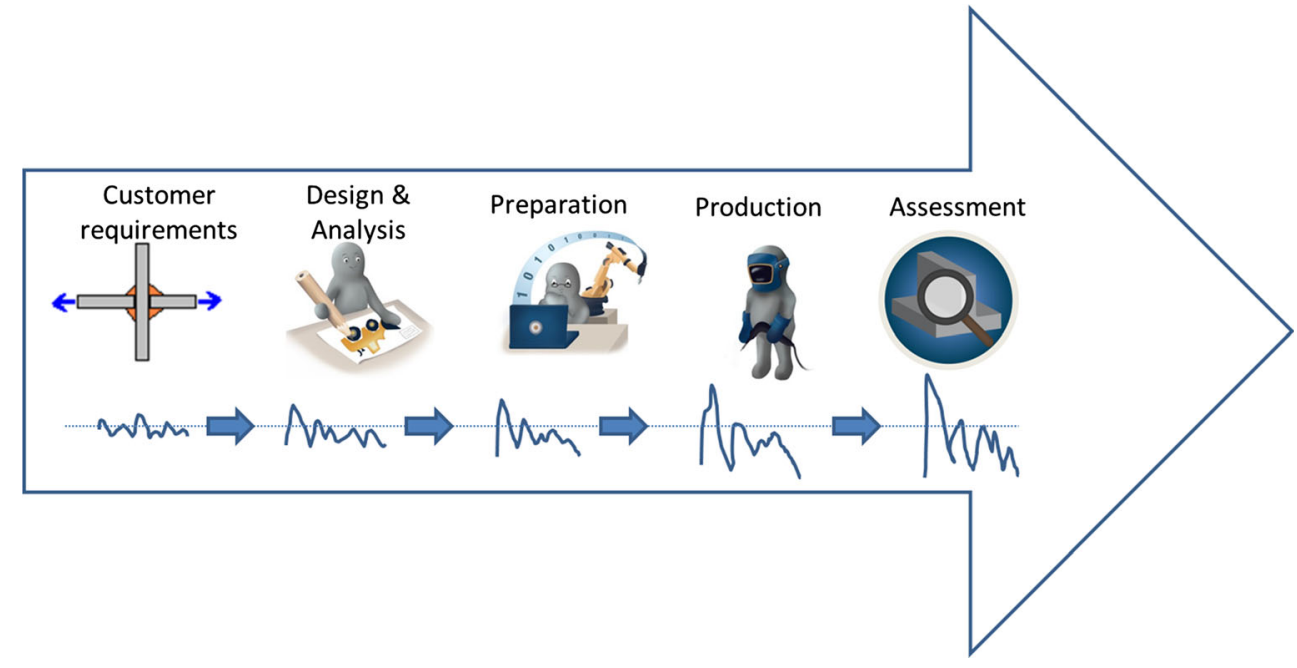

The variation in thickness of the raw material can serve as an illustration. The thickness variation of plates is initially small but increases when subjected to bending. Variation of bent parts makes it difficult to tack weld the parts, creating a variation in gaps of the weld joint. The method used by the operator to handle this further increases the variation. Some welders try to avoid the gap; others place a root seam of various sizes. The robot is programmed to weld the same amount of material, in the same way, every time. In reality, the robot needs to handle different joints, with small gaps and joints with a root seam of unknown size. The weld result becomes unpredictable, meaning that several types of discontinuities can occur. After robot welding, some welders repair those discontinuities and others do not. Finally, there is inconsistency in the judgments of the welds. Welds that should be accepted are not, and welds that should be rejected are accepted.

Table 1 show studies performed at the case company illustrating variation and its consequences in the different process steps. In the following sections, each step of the value stream will be discussed from a variation point of view. The financial consequences of variation will be exemplified.

\subsection{Customer requirements}

The risk of failures of welds relates to the scatter in load, requiring certain strength, among customers and the variation in the strength of the structures produced as shown in Fig. 3. The difference in customer usage determines the load distribution. The strength distribution is related to the sensitivity of the design and the scatter in the production and welding process.

Where the distribution curves overlap, failures can occur, for example, when customers with tough applications meet products with a low strength. The load distribution is assumed or based on measures at customers. The strength distribution is assumed based on historical data and experiences, since data of failed parts are rare. To test welded structures is typically very expensive and difficult.

\subsubsection{Potential related to customer requirements}

Uncertainties in customer usage and in product strength make it easy and also necessary to have safety margins to avoid failures. This results in structures that, on average, have a much higher strength than needed. From a quality and financial perspective, it is hard to make any general savings in this step. More information is needed regarding the strength distribution. It is necessary to be aware of the fact that the design is based on the most demanding application. Customization of the structures and focused sales efforts could make it possible to match structures with high strength to customers with demanding applications.

The trends in the industry such as commonality and modularizations are examples that can contribute to unnecessarily stringent requirements in relation to customer needs.

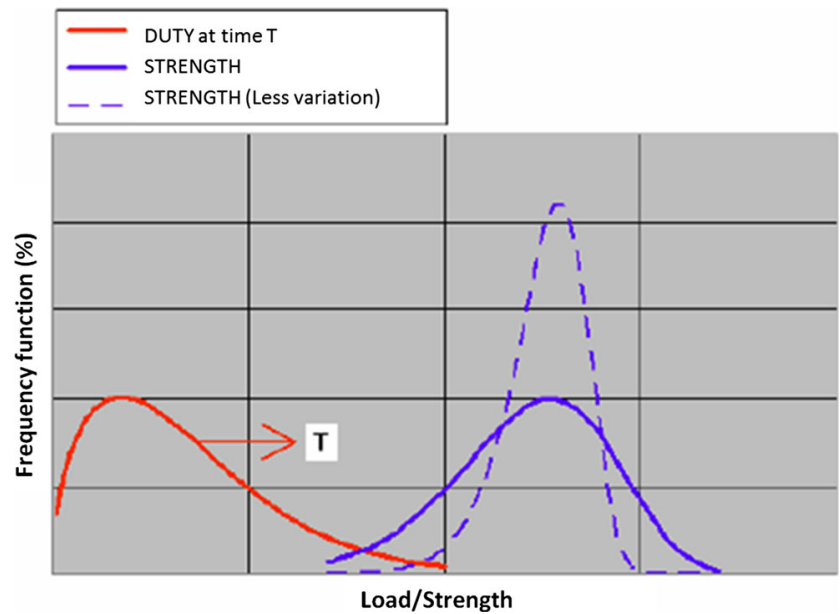

Fig. 3 Load and strength distribution over time, T. Overlapping curves indicate the failure rate 
The same structures or modules are used in applications with a large scatter in the expected load. As an example, the requirements are set for a structure with a load index of 100 . The same welding requirements are used for a structure with a load index of 67. This results in an expected life, at least, three times longer than needed for the structure with a load index of 67 based on the fact that an increase in strength of $25 \%$ corresponds to an increased life by a factor of 2 [4]. The commonality creates benefits in the production, but it is worth ensuring that those benefits exceed the added cost for increased strength. At the case company, it can be assumed that the average strength could be reduced by at least $10 \%$, which can be translated to approximately $20 \%$ less welding. This relates to the fact that the first $20 \%$ of the weld metal in a joint contributes more to the strength than the last $20 \%$. For a fillet weld with a throat thickness of $5 \mathrm{~mm}$, the first $20 \%$ gives a weld with a throat thickness of $2.5 \mathrm{~mm}$ plus additional penetration. The last $20 \%$ only adds $0.5 \mathrm{~mm}$ to the throat thickness, corresponding to less than $10 \%$ of the fatigue strength according to Olsson et al. [26].

The potential for further calculations is $20 \%$ less welding material needed, considering that requirements are based on heavier applications than necessary.

\subsection{Design and analysis}

According to Hoffenson et al. [27], designers typically judge how much variation in the product dimensions should be allowed while still maintaining a perception of high quality. This is however rarely based on a quantitative understanding of how consumers actually perceive variation and quality. In the case of welding, the customer requirement of welds is probably secondary; it is the function of the welds the buyer is interested in, that is, to join the parts together. This is stated in the following citations: "A good weld is any weld which does the job it is intended for during the entire life of the structure" [16] and "A good weld is a weld which adequately fulfills all its service requirements" [28].

The design engineers set the major cost of the structure by determining plate thickness, the number of welds, weld type, need of joint preparation, dimensional requirements, and so on. Johnson and Kirchain [29] exemplify this by a material change, which can alter the available design space, enabling increased performance even across multiple performance criteria (e.g., higher strength, reduced cost, and decreased weight). It can also radically change the set of appropriate manufacturing processes, which alters both the ultimate physical form of the product and the composition and configuration of the supply chain. This, of course, influences the total cost. Wahba [30] estimates the design cost at $5 \%$, but, on the other hand, the design represents $70 \%$ of the possibilities to reduce cost. Depending on experience and skills, the designers have different possibilities for utilizing the $70 \%$ potential.
The first factor that affects the cost is the possibility to make robust designs, insensitive to variation. This makes it possible to fit the parts together without oversized and/or varied gaps. Oversized or varied gaps in the joint make it difficult to get predictable weld quality by robot welding and require additional attention from the welders, either before or after the robot welding operation. Secondly, the specified weld size is a factor that directly corresponds to the welding time. It is essential to specify the correct throat thickness and to avoid joint preparations [9].

\subsubsection{Potential related to analysis and design}

It is not easy to obtain figures on how unsuitable the design solutions are. Closest to the truth is probably to measure the over-processing in production that can be related to design solutions. On larger structures, it is common to use the same weld designation almost everywhere, e.g., all fillet welds have the same throat thickness and weld class. This is very convenient in design and in production, but it also contributes to more welding than necessary. In addition to extra consumables and production time, it also means more heat input leading to more distortions. With more customized throat thickness requirements, the needed welding could be significantly reduced.

A study of a structure at the case company showed that it was possible to reduce the weld metal weight by $28 \%$, without affecting the fatigue strength. This was possible by softening requirements in areas with low stress. The potential saving corresponds to a throat thickness reduction of $1 \mathrm{~mm}$, from 5 to $4 \mathrm{~mm}$, applicable for $78 \%$ of the weld length.

The potential for further calculations is $28 \%$ less welding due to reduced requirements in low-stress areas.

\subsection{Production}

This section includes the activities conducted after the design has been released until the welded structure is produced and ready for the customer. The activities have been divided into preparation, welding, and assessment.

\subsubsection{Preparation}

The requirements stated on the drawing need to be translated into production operations. In this section, the consequences of variation in the development of welding procedure specification (WPS), robot programming, and instruction preparation will be highlighted.

In many welding companies, creating a WPS is a part of the preparation process. A WPS specifies material, wire, shielding gas, and other parameters that should be used to achieve the required result. The WPS is qualified, which means that test pieces are produced and tested to see if the described settings 
will give the desired outcome. This process has several builtin sources of variation.

Firstly, the person creating the initial preliminary WPS chooses to use certain values, based on previous experience and the existing WPS. Another person could choose other values to start with. This has been verified in a research project in which the case company participated. Five different weld shops created a WPS for the same weld. The deposition rate varied between as much as 3.8 and $7.5 \mathrm{~kg} / \mathrm{h}$.

Secondly, the test samples created in the qualification process also vary.

Finally, the values stated in the WPS have tolerances. That means that the resulting products can be welded with slightly different values, still according to the WPS.

Robot welding is common for industrial use. The robot programmer uses the WPS and compensates for varying gap sizes, and thereby varying welded joint volumes, by making the weld larger. Other requirements affected by variation in the process, like smooth weld toe radius and equal leg length, are commonly handled by adding safety margins, for example, by running the robot with reduced speed. If several persons carry out programming, there is variation in the level of compensation between operators based on experience and feedback from later process steps.

Manual welding operations are often supported by an instruction supplementing the drawing. The instruction can state where to tack weld or complete welds that cannot be finalized in the robot welding operation. Depending on the knowledge of the person making the instructions, they vary in, e.g., number and size of tack welds.

\subsubsection{Welding}

Welding is a process with a large scatter, and the people in the process add safety margins so as to never fall below the specified value. To simplify the situation, one can say that the plates and the way the weld is applied can vary. Because of plate tolerances and chosen designs, gaps can occur. Three main issues can be identified in case of gap variation.

Firstly, a big gap increases the risk of burn-through in the robot, meaning that the weld collapses and leaks out on the other side. That results in robot downtime, manual repairs, and additional welding. However, a study conducted by Ericson Öberg et al. [22] showed that up to $47 \%$ of the investigated sub-assemblies had an extra weld, a root pass. The reason for that was mainly to prevent the robot from burning through due to the wide gap. This added cost and had a strong influence on resource efficiency since the additional operation also added consumables and increased production time. The root pass is not always added, and that variation in itself is costly. This creates an imbalance in the production line, causing longer operation times or production interruptions.
Secondly, the risk of weld defects increases. Because of the shape of the weld, solidification cracks, also known as hotcracks, can occur. In a deep, narrow joint, impurities can be trapped in the middle of the weld, which can break under the influence of shrinkage stresses [10]. If a root pass is made manually to compensate for the different gaps, the operation adds variation, e.g., the size of penetration depth. The variation in root pass execution also creates changing conditions for the welding robot, affecting the result and the need of repairs and other manual operations afterward.

Finally, the gap size affects the resulting throat thickness, and the organization tries to compensate to reach the required size. There is a belief that a larger weld would be stronger; this is, however, untrue according to Cozens [31]. The consequences are increased welding consumable usage and longer operation time.

\subsubsection{Assessment}

Quality assessments of welds are carried out continuously during the production by the welder as well as afterward by auditors.

At the case company, the parts are sent to final welding after the robot welding. In this production step, operations are done that cannot be performed earlier in the value stream. There are mainly three types; attachments are added, small welds are performed, and defects are repaired. Weld start/stop, corners, undercuts, and weld toe radius are the most commonly repaired at the case company. In the case described, many repairs are done by routine rather than by the actual need. The welder wants to be on the safe side, preferably repairing too much than the opposite.

To evaluate how the need of repairs was perceived by the final welders, a test was performed. Possible defect areas, 20 in total, were located on a structure which had been welded by a robot. Ten experienced welders who work with these products daily were asked if they would make a repair or not. They looked at the welds in random order, and then the procedure was repeated again after $1 \mathrm{~h}$. A professional auditor then made an evaluation of the welds according to the requirements and gave a professional judgment. In total, 400 answers were collected.

The repeatability of the individual welders' answers was $94 \%$, varying between 100 and $85 \%$. Seventy-five percent of the welds were accepted by the auditor, but the welders would have repaired $62 \%$ of those. Twenty-five percent were not accepted and should be repaired according to the auditor. The accuracy among the welders was $85 \%$, but this means there are defective welds not being repaired.

When the final welder decides on action, the cost is strongly influenced. As the investigation showed, two thirds of all decisions about repairs were unnecessary. The potential of productivity improvements is great. On the other hand, almost 
one fifth of the necessary repairs were missed. If that leads to a breakdown, the cost is very high. By removing two thirds of the repairs, the risk of missed repairs increases. The variation in judgment also influences the workload and balancing of the production flow. If the operations are set up according to the worst-case scenario, waste in the form of, for instance, waiting, inventory, and transports, is introduced in the system. The problem is again the variation.

The variation in assessment creates an incentive for the organization to over-process. A test part at the case company was OK according to the standard but was commonly considered as defect. It was welded at a $30 \%$ higher welding speed, giving a production cost of only $76 \%$ of the commonly accepted sample. A change in the welding process would also make it possible to produce $19 \%$ more in the current welding robot.

Another investigation, described by Ericson Öberg and Åstrand [24], indicates similar results. The 43 participants in the inquiry were divided into four categories depending on their profession and experience in welding: designers, welders, quality staff, and customers. The category "customers" was represented by people working with final inspection of the assembled machine. The participants were to evaluate ten welds and decide if the weld quality was good, acceptable, not acceptable, or not acceptable and in need of repair.

The result showed a vast variation in judgment between the participants, both between and within the categories. The answers covered the whole range of judgment selections for most samples. The investigation indicates that the closer to the fabrication the appraiser is, the more demanding it is. The customer representatives, as well as the designers, were more satisfied with the quality than the welders.

A certain percentage of the parts produced at the case company is assessed by auditors. The part is $100 \%$ evaluated according to the requirements. An investigation reported by Ericson Öberg and Åstrand [24] indicates that there is a variation also in the auditors' judgments. Sixteen auditors from 12 factories in 7 countries in the same company evaluated 16 welds. For each weld, the auditor was to decide if the weld was defect-free or not and how severe any defect was (four levels). All auditors evaluated the same weld three times resulting in a total of 11,520 answers. The result shows tiny values of Kendall's coefficient of concordance, 0.42 , meaning that the auditors had severe problems classifying the welds with strong agreement [24].

There is also a risk that measurement system analysis is not performed at all for the evaluation methods used. That means that the organization is unaware of the variation caused by the measurement system itself. The organization, therefore, reacts on measurement noise as if it were a real change in the process, inducing more variation.

The variation in audit assessment also introduces overprocessing into the process. If there is a deviation reported from the audit, the production staff try to compensate. If the variation in assessment creates a false incentive to change, over-processing is created.

Finally, there is also a risk that single measurements or evaluations, with a significant variation, are improperly used for controlling the process. The dimension of natural variation gets lost, and the organization might overreact to common causes, all in vain.

\subsubsection{Potential related to production}

The additional weld volume generates a corresponding cost increase in the form of additional consumables and production time. In the case company, a WPS for a 5-mm fillet weld created welds with a throat thickness of $5.4 \mathrm{~mm}$. This means that $17 \%$ extra welding is specified already in the welding preparation. That figure is probably higher caused by a concave or convex shape [21].

A study conducted by Ericson Öberg et al. [21] showed a significant difference in consumable usage, more than $40 \%$ extra between the theoretical and the actual value for robot welding. The causes of the difference had mostly nontechnical characteristics, like information transfer between the functions regarding whether the compensation for varying gaps should be made in the WPS or in the robot. The overprocessing in the range of $40 \%$ in the robot could be verified in a related study. An even more remarkable result in the study was the amount of extra weld metal weight in the manual welding operations, which was over $100 \%$. This relates to over-sized welds, repairs, and compensation for variation in gaps, which ideally should not be needed. Considering manual and robot welding, the average over-processing, measured in weld metal weight, was $48 \%$.

Over-processing with too much welding is a hidden waste in production; it is not noticed since it is natural to believe that value is added during welding. Also, the welder believes that he or she adds value to the product. The problem is, however, who takes the cost of doing things better than good enough? If neither the producer nor the customer is willing to pay, the over-processing is a waste.

The potential for further calculations is $32 \%$ less welding due to reduced over-processing.

\section{Analysis of results}

The identified saving potential relates to reduced variation in several steps. Customer needs could be differentiated to avoid that all structures would have to meet the requirements for the toughest application, especially when the same structures and welding requirements are utilized for modules or applications with a significant difference in intended load capacity. This 
gives a general load reduction that can reduce the level of requirements.

In design and analysis, the potential is not in introducing a general reduction. Instead, the potential can be found in the reduction of weld size and weld quality level outside the critical high-stress areas of the structures. The requirements on long welds can be differentiated to avoid that a particular spot sets the constraint for the entire length.

In production, the potential can be found in the reduction of variation and over-processing. In a perfect situation, the production is controlled towards the nominal value and the variation is handled by the allowed tolerances in the weld quality standards.

The potential is shown in Fig. 4. Theoretically, more than half of all welding could be removed by reducing overprocessing and improving requirement settings.

Considering the arc-on factors of manual and robot welding at the case company, the weld metal weight reduction could give a total time decrease in the production of approximately $30 \%$ (based on Formula 1). The time reduction could also increase the production capacity with the existing setup by $43 \%$.

Wahba [30] has presented a cost distribution of a product between design, material, burden, and labor, based on the assumption that the welding cost could affect the direct labor cost and half of the burden cost. These parts represent $30 \%$ of the total cost of a manufactured part. If the labor cost could be reduced aligned to a time saving of $30 \%$, the total cost reduction potential of a welded structure is around $9 \%$. Additional cost savings can be made by the reduction of welding consumables and a decrease of the burden cost due to increased productivity, at least by $1 \%$. In total, the cost reduction potential of welded structures is more than $10 \%$ for adopted requirements and reduced over-welding.

\section{Discussion}

The studies conducted clearly show the existence of variation in each process step and the financial influence of it. It is also clear that the issues have cross-functional characteristics, meaning that the possibilities to address them in each function are limited. The overall picture gets lost when processes are handled as individuals with limited connection to each other, and thereby many opportunities are lost. The studies also indicate that the variation concept is not generally handled at the plants. It is unknown whether the causes of problems stem from a stable or unstable process. Since the problems require different solutions, this situation leads to faulty decisions, improper actions, and over-processing. This lack of understanding strongly influences the cost.

One main problem is that there is no clear-cut definition of weld quality cost. This creates problems and symptoms that are difficult to give priority to because it is not clear what financial impact they have. Each department/function has its own definition of weld quality and operates by various metrics. Cost is the common denominator, the language everyone understands, which can give incentives for cross-functional initiatives.

The variation in customer usage, even though to some extent unknown, could be handled by offering heavy-duty welded solutions in the same way as additional equipment. Currently, many of the products are over-specified according to their usage, driving costs. By providing flexible weld solutions, the over-welded parts could be reduced in most of the products. On the other hand, there is a mix-up risk, and an increased number of models could also give greater complexity and more work in progress. According to [32], there is a trade-off between the level of flexibility available in the system and the associated complexity and operating costs. The challenge is to have the "right" level of flexibility to capture
Fig. 4 Potential for reduction of weld metal weight in the process of welded structures

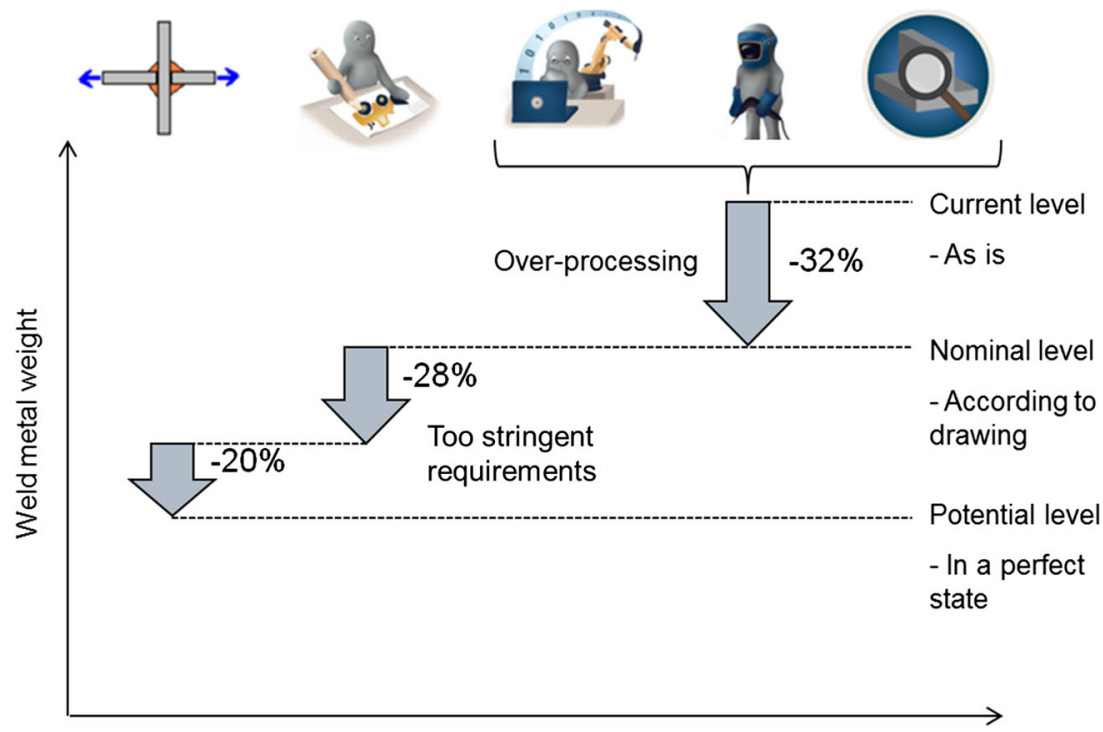


the benefits from a fully flexible system while controlling the increase in implementation costs. A slight increase in process flexibility can lead to a significant improvement in system performance [32].

The design expects a distribution around the specified requirement target, e.g., throat thickness. Production, however, strives not to be below the target, creating large, unknown safety margins. The total variation through the entire value stream becomes significant because each step builds on the previous variation.

In production, it can be questioned whether the repairs carried out always make the weld better. Take an undercut at a weld toe with a longitudinal stress direction, parallel to the undercut, as an example. If we repair the local undercut, stress concentrations will be introduced perpendicular to the stress direction at the start and stop of the repair. It is not even sure that the repairs are needed or influence structural integrity at all.

It can be problematic to change the way of working and start to produce exactly according to the drawing. If the process previously has delivered higher quality than required, there is a risk that the design solution is seen as good enough even though the weld would break if executed exactly as in the drawing. That is a consequence of having unknown safety margins, and a reduction should be made in a controlled manner.

There is a risk that audits become an everyday task. Forgetting the purpose is easy. One needs to ask, "How will this assessment help us to improve?" Another important issue is the effect over-processing has on the future development of the company. The additional time spent could instead be used for business development or production of other parts. The uncertainty of the existing safety margins could limit the development. New solutions will not be implemented due to the perceived risk of failures.

The key to improvement is knowledge. As soon as the current state is known and it is evident how much variation each step adds, we can start doing something about it, if necessary. Table 2 defines the main problems, consequences, and possible actions in the different process steps.

One of the main challenges in quality assurance and quality control is to identify what welds will do the job, and what welds will not. For this purpose, a process including quality assurance, drawings, welding standards, design guidelines, design and analyses, and functional requirements of the customer needs is created. This process is illustrated in Fig. 5. It can be assumed that the customers never want failures of a welded structure, neither does a producer of welded structures. On the other hand, it is problematic to design and produce structures with an eternal life. That would result in weighty and expensive products, which the customers would not like to buy. The producer instead has to create limitations and take a calculated risk of failures. This is done through a certain 
Fig. 5 Flaws in the process create a flow that varies between $\mathrm{OK}$ and not $\mathrm{OK}$ (NOK) as a sign of weak or missing connection between the different steps in the process

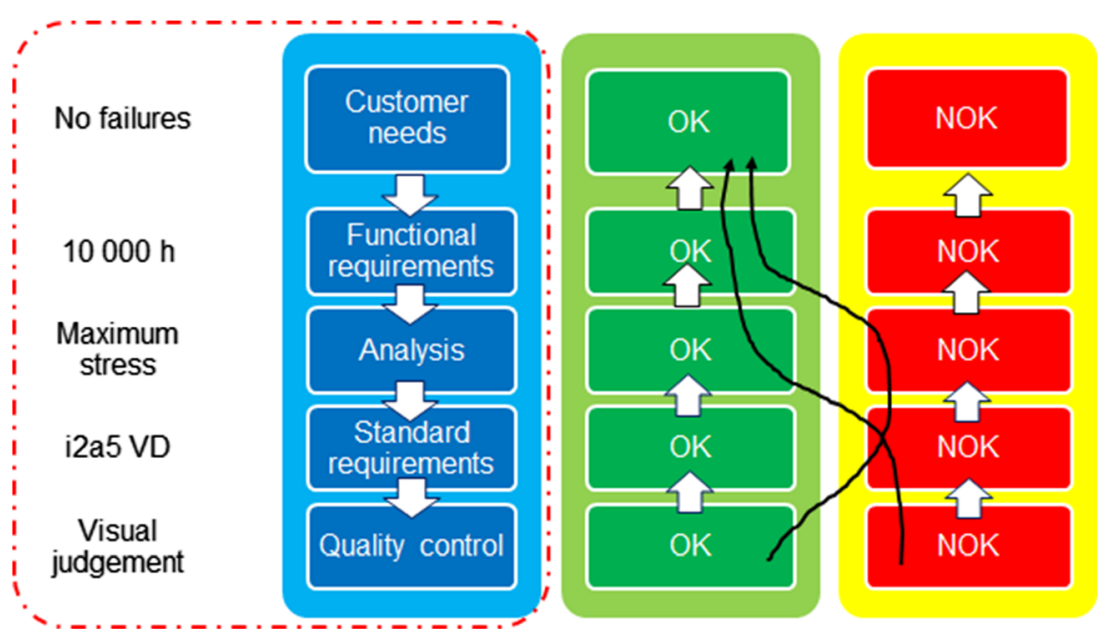

limitation in cycles, hours, or years. In the design process, these limitations are used to set the welding requirements to meet the needs. In production and quality assurance, these requirements are inspected, often visually.

The difficulty in the breakdown of the requirements is to have a high quality in the process to secure that an accepted weld in the quality control is also accepted in the loop back to the customer needs. The black arrows in the figure show examples of potential and common paths. Ideally, these arrows should be straight and not vary between OK (approved according to specification) and NOK (not approved according to specification). If they vary, it is worth considering improving and aligning the process within the dotted square in Fig. 5. The first step to improve is to find a common, communicated view of the customer need. Management across different functions need to agree on the intended product life and make decisions thereafter.

\section{Conclusions}

This paper highlights the hidden potential of reduced manufacturing cost of welded structures through reduced variation and customized requirements. All process steps, customer requirements, design and anlysis, preparation, welding, and assessment all induce variation and thereby cost. Theoretically, in a perfect situation without variation, more than half of all welding could be removed resulting in reduced production time, increased productivity, higher flexibility, and reduced cost. The most important findings are as follows:

- Variation in the different processes, causing stringent requirements and over-processing, strongly influences the cost.

- The practical implications described are substantial; in an ideal situation, half of the welding could be removed.

- It is possible to achieve a cost reduction around $10 \%$ and a production capacity increase with over $40 \%$.
- An interdisciplinary effort is essential to address these issues successfully.

The research conducted relates to gas metal arc welded structures with a majority of fillet welds with a throat thickness of at least $5 \mathrm{~mm}$. Future research could build on this knowledge to investigate whether the result is applicable to other types of welding and manufacturing methods. Future research could also investigate the identified sources of variation and study how they could be reduced. This requires indepth knowledge of all process steps and collaboration between industry and academia. The need of a cross-functional and holistic view necessary to address these issues is a challenge to many organizations due to the organizational structure and history. That makes this a research area with big potential.

Acknowledgement The research work being the base of this paper has been partly funded by Vinnova, the Knowledge Foundation, and Volvo. A great contribution has been made by the staff at the Volvo CE Arvika and Braås plants.

Open Access This article is distributed under the terms of the Creative Commons Attribution 4.0 International License (http:// creativecommons.org/licenses/by/4.0/), which permits unrestricted use, distribution, and reproduction in any medium, provided you give appropriate credit to the original author(s) and the source, provide a link to the Creative Commons license, and indicate if changes were made.

\section{References}

1. Björk T, Samuelsson J, Marquis G (2008) The need for a weld quality system for fatigue loaded structures. Weld World 52:3446. doi:10.1007/BF03266615

2. Åstrand E, Öberg AE, Jonsson B (2013) Cost affecting factors related to fillet joints. In: Jármai K, Farkas J (eds) Des. Fabr. Econ. Met. Struct. Springer Berlin Heidelberg, Berlin, Heidelberg, pp 431-435

3. Hobbacher AF (2009) The new IIW recommendations for fatigue assessment of welded joints and components - a comprehensive 
code recently updated. Int J Fatigue 31:50-58. doi:10.1016/j. ijfatigue.2008.04.002

4. Jonsson MB, Samuelsson PJ, Marquis PGB (2011) Development of weld quality criteria based on fatigue performance. Weld World 55: 79-88. doi:10.1007/BF03321545

5. Marquis G, Samuelsson J (2005) Modelling and fatigue life assessment of complex structures. Mater Werkst 36:678-684. doi:10. 1002/mawe. 200500938

6. Marquis G, Björk T, Samuelsson J (2006) Toward a weld quality system for fatigue loaded complex structures - XIII-2103-06

7. Koufteros X, Lu G, Peters RC, Lai K, Wong CWY, Edwin Cheng TC (2014) Product development practices, manufacturing practices, and performance: a mediational perspective. Int J Prod Econ 156: 83-97. doi:10.1016/j.ijpe.2014.05.017

8. ElMaraghy HA, AlGeddawy T (2012) Co-evolution of products and manufacturing capabilities and application in auto-parts assembly. Flex Serv Manuf J 24:142-170. doi:10.1007/s10696-0119088-1

9. Stenbacka N (2009) Svetsekonomi och produktivitet, 1st edn. Svetskommissionen, Stockholm

10. Weman (2003) Welding processes handbook. Woodhead Publishing, Cambridge, Eng, Boca Raton, FL

11. Hammersberg P, Olsson H (2010) Statistical evaluation of welding quality in production

12. Åstrand E (2015) A new innovative toolbox for lean welding of fatigue loaded structures. Int J Adv Manuf Technol. doi:10.1007/ s00170-015-7183-2

13. Nykänen T, Li X, Björk T, Marquis G (2005) A parametric fracture mechanics study of welded joints with toe cracks and lack of penetration. Eng Fract Mech 72:1580-1609. doi:10.1016/j. engfracmech.2004.11.004

14. Gregory N (1992) Weld flaws - do they matter? TWI Bull. 1992

15. Shaw R (2011) Comparison of ISO 5817 quality criteria to that of national standards - surface imperfections, IIW Doc. XIII-2392-11

16. Miller DK (1997) Ensuring weld quality in structural applications part III. Weld. Innov. 1997

17. Wheeler DJ (2000) Understanding variation: the key to managing chaos. SPC PRESS, Knoxville, Tenn

18. Bergman B, Klefsjö B (2010) Quality from customer needs to customer satisfaction, third edn. Studentlitteratur AB, Lund
19. Masmoudi F, Bouaziz Z, Hachicha W (2007) Computer-aided cost estimation of weld operations. Int J Adv Manuf Technol 33:298 307. doi:10.1007/s00170-006-0463-0

20. Stemp J (2012) Fatigue assessment of a hauler bogie beam using FE analyses - master thesis work. Technical University of Munich, Munich

21. Ericson Öberg A, Martin J, Holm EJ, Hammersberg P, Svensson LE (2012) The influence of correct transfer of weld information on production cost. In: Chalmers Publ. Libr. CPL, pp 295-302

22. Ericson Öberg A, Wikstrand S, Mattson V (2014) Impact of gaps on resource efficiency in heavy welding industry

23. Perez Sota E, Qollakaj K (2015) Production cost prediction of welded structures. Master Thesis, Blekinge Tekniska Högskola

24. Ericson Öberg A, Åstrand E (2013) The subjective judgement of weld quality and its effect on production cost. In: Jármai K, Farkas J (eds) Des. Fabr. Econ. Met. Struct. Springer Berlin Heidelberg, pp 621-626

25. Nykänen T, Marquis G, Björk T (2009) A simplified fatigue assessment method for high quality welded cruciform joints. Int J Fatigue 31:79-87. doi:10.1016/j.ijfatigue.2008.02.016

26. Olsson KE, Holm D, Jakopovic F (1997) High strength welded box beams subjected to torsion and bending fatigue loads - mode I and III stress intensity factors and crack growth predictions

27. Hoffenson S, Dagman A, Söderberg R (2015) Visual quality and sustainability considerations in tolerance optimization: a marketbased approach. Int J Prod Econ 168:167-180. doi:10.1016/j.jpe. 2015.06.023

28. Dawes C (1992) Laser welding: a practical guide. Woodhead Publishing, Cambridge

29. Johnson M, Kirchain R (2009) Quantifying the effects of parts consolidation and development costs on material selection decisions: a process-based costing approach. Int J Prod Econ 119: 174-186. doi:10.1016/j.ijpe.2009.02.003

30. Wahba (2010) Lean, integrated product \& process development. http://slidegur.com/doc/1438316/lean-integrated-product-\%26process-development. Accessed 25 Aug 2015

31. Cozens M Fillet welded joints - a review of the practicalities - job knowledge 66. In: TWI. http://www.twi-global.com/technicalknowledge/job-knowledge/fillet-welded-joints-a-review-of-thepracticalities-066/. Accessed 24 Nov 2015

32. Chou MC, Teo C-P, Zheng H (2008) Process flexibility: design, evaluation, and applications. Flex Serv Manuf J 20:59-94. doi:10. 1007/s10696-008-9053-9 